\title{
COMMENTARY
}

\section{Post Covid-19 urbanization requires new standards and per capita in planning, design, and building}

\author{
Abdol Aziz Shahraki \\ Knowledge \& Implementation Consulting Engineering Co. Zahedan city, Iran
}

\section{Check for updates}

Correspondence to: Abdol Aziz Shahraki, Knowledge \& Implementation Consulting Engineering Co. Zahedan city, Iran; E-mail: aa.shahraki@yahoo.com

Received: September 15, 2021;

Accepted: November 1, 2021

Published: November 4, 2021.

Citation: Shahraki AA. Post Covid-19 urbanization requires new standards and per capita in planning, design, and building. Soc Work Soc Welf, 2021, 3(1): 167-171.

https://doi.org/10.25082/SWSW.2021.02.004

Copyright: () 2021 Abdol Aziz Shahraki. This is an open access article distributed under the terms of the Creative Commons Attribution License, which permits unrestricted use, distribution, and reproduction in any medium, provided the original author and source are credited.

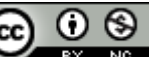

\begin{abstract}
This paper studies investment reductions in urban health protection programs in the recent decades under the umbrella of plutocratic ideas. It studies the densely populated slums with little urban spaces, narrow sidewalks, traffic jams, and degraded environmental components. This paper addresses the question of how shall we reopen post-covid-19 cities sustainably and lively? Our method to find a solution is an innovative mathematical model that suggests revision in the current regulations and standards, sizes, and per capita of urban spaces with the help of maximizing necessary investments. This paper analyzes crowded neighborhoods, urban transport sites, and polluted environments where people cannot respect world health organization protocols concerning individual and public health protection. This research aims to maximize investment in public health protection for supplying suitable urban places' sizes. Outcomes of this research will be helpful to reopen cities in the post-Covid-19 everywhere in the world.
\end{abstract}

Keywords: Covid-19 disease, urban health protection, regional/urban development, regulation

\section{Introduction}

Urbanization has evolved with the development of regulations and standards on social cooperation, common public interests, and empathy. Modern urbanization is closely associated with the reorganization of the urban economy. Urban land-use policies have been fundamental instruments in the reform of urban economies to progress the life quality and urban health protection [1].

With the discovery of the Covid-19 disease vaccine, its medicine, and the past year's experiences, the sparks of hope have surged in the reopening of urban public places and activities. Historically, the continued development of urbanization with increasing attention to public health protection has had significant achievements. One of the advantages of reorganizing urban land-use policies in the postindustrial era has been allocation land for green spaces, wider streets and sidewalks, and modern transportation infrastructure. Another advantage of urban land-use reorganization has been an improvement of the urban life quality. Investment in medical care projects and health protection has also been one of the benefits due to land-use revisions.

However, in recent decades, the fever of saving public health protection costs has increased in many politicians and city managers. Results of decades of short investment have reduced the per capita urban land for health protection. Consequently, urban citizens have fewer individual and social health protection services. Some scholars verified that the declining health care investment in the expanding cities highlighted the health inequity associated with slums [2].

The global COVID-19 pandemic revealed that people do not have access to hygienic, medical, and healthcare services. They are without empty hospital beds, ventilators, clean weather, doctor, nurse, medicine, funds, etc. [3]. It is necessary to learn from the experience of the Coronavirus attack to reopen cities and urban economies. We hypothesize that more investments in urban health protection programs and land-use regulations to increase per capita for the sake of wider sidewalks, transport stations, urban spaces, and less densely populated neighborhoods will protect urban health optimally. The reasons are that social distancing and preventing close contacts of those infected or of carriers of the virus reduce the risk of Coronavirus infection [4]

The question addressed by this paper is what reforms in terms of regulation, planning, and design, rebuilding, and the new building is needed to safeguard the communities against future similar or worse risks and harms? The method of this research is a mathematical model that maximizes investment in urban health protection. Analytically, we suggest improvements that the urban health protection services require in the post-Covid-19 era. We will prioritize 
individual and public medical and health care services when formulating urban strategic economic policies. Cities need justice in the easy access of people to hospitals, doctors, medicines, vaccines, hygiene, and healthcare services. In the reopening, cities will be resilient against current and new coming pandemic diseases [5,6].

Post-pandemic cities need capacity building and resources to be resilient from medical and health protection perspectives. A way to meet this target is revisions in demographic development. Household consultation and population control proportional to local natural and economic resources are helpful [7]. Parallel to population planning, there is a need for revision in urban planning and building. Modifications in standards and increasing per-capita of urban spaces that limit the individual and social health protection are necessary. We anticipate that these measures will upgrade medical, hygienic, and healthcare services quantitatively and qualitatively [8]. We will increase Per-capita in residential quarters, sidewalks, housing, hospitals, schools, and other urban spaces upon professional engineering studies for the sake of reopening the cities without future likely risks. We were in common with the world health organization when it said readiness in cities is essential for reactions to Covid-19 [9].

From an architectural point of view, we shall change the dimensions of rooms, homes, buildings, hisses, stairs, escalators, ramps, toilets, and bathrooms with new sizes. We will also change the sizes of residential blocks, streets, sidewalks, bus stations, airport halls, passenger ports, and rail transport stations. The frontage shore of rivers, lakes, and seas needs similar changes. Hospitals and medicate sites, and urban healthcare locations need modification too. Similarly, we shall change per capita of classrooms, shopping malls, churches, mosques, temples, etc. Of course, the changes are verifiable aftermath of adequate research and examinations.

The mentioned spaces are just samples that require new standards and per capita. The new regulations and standards will prevent the density in the cities, traffic, and transportation places. Environmental components in the cities need upgrades via investment in water supply projects, clean air measures, etc. For example, urban wastewaters shall be collected and treated well. We need more inclusive actions due to urban health protection to reducing inequalities and prioritizing the needs of vulnerable groups. Digital and smart cities by automatization meet more social fairness [10]. The lack of proactive planning and emergency plans was a reason for the failure to respond to the Coronavirus attack effectively [11]. We are aware that the spread of the Coronavirus has caused macro socio-economic impacts. Therefore recovery and adaptation plans and policies are needed to rehabilitate the hurt cities [12].

\section{Field studies and experiences}

Experiences of the Coronavirus attack on the world exhibit that the restricting health protection services are catastrophic. Such policies led to the collapse of social relationships and economies in addition to taking human lives. The experience of people around the world against the Coronavirus was very shocking. Gradually, people became aware of the danger of the Covid-19 epidemic and endeavored to follow health protocols and physical distance. In the process, people realized that crowded places had become centers of death. Crowds in buildings, corridors, stairs, elevators, sidewalks, traffic jams, transportation stations, vehicles, workplaces, stadiums, cinemas, and restaurants could not distance themselves from each other. This inability was since cities had not been planned and designed for the presence of the Coronavirus or invading microscopic organisms.

Since the Covid-19 crisis, we have strived to recognize the role of slums, traffic jams, degraded environmental components, etc. One study examined and proved the impact of population density on the spread of the Covid-19 pandemic in Nigeria and Italy with two sociodemographic patterns [13]. In the first three months of the Covid-19 global pandemic, large and dense urban areas such as New York, Madrid, and London were disease hotspots [14].

Crowds of people where it was hard to stay spaced at least two meters apart posed the highest probability of an outbreak of the disease. The larger the group and the longer people were together in these situations, the higher the risk. We saw people who could not respect the WHO protocols due to population-dense and short urban spaces. We experienced that inadequate urban spaces and sidewalks were the cause of the spread of Covid-19 disease. We also found out urban physical infrastructures and institutions that need improvements before reopening [15].

Urban planners should also re-examine the skeletal design of the built environments. They might integrate safe-distancing sizes into street and building designs with more walkways and parks [16]. Mass populations of the poor who had no more interests than food were directly at risk of infectious diseases. They could not be even 10 centimeters apart, let alone the 2 or 3 meters recommended by the world health organization. 
Untreated urban wastewater spread Covid-19 disease. We recognized the importance of supplying qualified water for built environments and collecting and treating urban wastewaters $[17,18]$. Studies suggested that Coronavirus existed in the wastewaters $[19,20]$. The polluted environment caused the spread of Covid-19 disease as well. Scientists studied Coronavirus relationship with environmental factors. Studies suggested that unsustainable environmental management contributed to an increase in zoonotic diseases [21].

From an economic perspective, we experienced huge losses due to the Covid-19 disease. Scientists suggested recovery pathways for the aviation industry, tourism, production factories, agriculture, education, etc. [22,23]. Scientists analyzed the economic and social impacts of the lock downed cities to reopen resiliently. They reviewed lessons learned in digitalization, mobility, density, and urban design to build back better cities [24].

The unpreparedness of urban management led to the spread of Covid-19 disease too. Macao was one of the first cities in China that experienced unpreparedness and went into lockdown. Macao experienced a half-year lockdown with substantial government subsidies [25] .

Regarding what we learned from the Coronavirus invasion in the global community, we acknowledge that regulations, suitable standards, and per-capita of urban spaces require revisions for the sake of urban health protection.

\section{Findings and discussions}

The experiences of Covid-19 disease epidemiology declared that protocols to keep urban health, including the physical distance, require new legislation, standards, per capita, and funding measures require new looks.

We confirm that plutocracy in the supplying of urban services reduced the investment in urban health protection services. To model post-Covid-19 urban economies on a spatial network, we introduce specific rates of urban health protection at given demands and supply capacity of cities as following:

$U H P_{j}^{r}=$ Rate of urban health protection $r(r=1,000, \ldots, m)$ in surplus demand urban place $j$ of the city.

$U H P_{i}^{r}=$ Rate of urban health protection $r(r=1,000, \ldots, m)$ in surplus supply urban place $i$ of the city.

$T U H P_{i j}^{r}=$ Rate of urban health transaction when delivering from surplus supply place $i$ to surplus demand place $j$.

Expressed formally, an equilibrium relationship between urban social groups in a network of urban places has the following conditions for any pair:

$$
U H P_{j}^{r}-U H_{i}^{r} \leq T U H P_{i j}^{r} \quad \text { For }\{j=1, \ldots, n\} ;\{i=1, \ldots, n\} ;\{r=1, \ldots, m\} ;
$$

Associated with the conditions between pairs of places there is an equal maximization of the rate of urban health protection as following:

$$
\begin{gathered}
\text { Maximize } \sum_{i j r}\left[U H P_{j}^{r}-T U H P_{i j}^{r}\right]_{x_{i j}}^{r} \\
\text { subject to } \sum_{j}{ }_{x_{i j}}^{r} \leq \bar{x}_{i}^{r} ;\{i=1, \ldots, n\} ;\{r=1, \ldots, m\} ;
\end{gathered}
$$

In the target function above, the rates are endogenous variables. The conditional inequality function shows the health protection rate of a city and a place in it. When equity exists, the rate will be a positive number and acceptable. Similarly, an unacceptable urban health protection rate equals zero or a negative number. With the help of the upper model funding for urban health protection in the post-Covid-19 era of urban planning, design, and the building will meet more optimal and fair outcomes. The result will be versus the current rule of plutocracy, which declines the rate of urban health protection. By applying the upper model, post-covid-19 cities will maximize investment in urban health protection services. Consequently, the model contributes to set up new regulations, standards, and per capita to housing and urban planning and design sustainably.

\section{Conclusion}

This study analyzed why the world experienced the emergence, continued presence, and irreparable damage caused by Coronavirus. We declared that in recent decades the prevalence of the idea of savings by promoters of plutocracy has drastically reduced investment in social 
and personal health protection programs. We hypothesized that large unplanned populations in slums and tight urban spaces spread the Covid-19 disease to the entire global community. We saw that people in crowded neighbourhoods, traffic jams, and polluted environments could not follow world health organization protocols concerning individual and public health protection.

Our proposed mathematical model, along with appropriate legislation, standards, and per capita, can maximize investment in maintaining social health in cities after reopening. The model presented in this research, recommendations, and its outcomes assist the cities in the post-Covid-19 age everywhere in the world.

\section{References}

[1] Frank LD. Land use and transportation interaction: implications on public health and quality of life. Journal of Planning Education and Research, 2000, 20(1): 6-22. https://doi.org/10.1177/073945600128992564

[2] Vlahov D, Freudenberg N, Proietti F, et al. Urban as a determinant of health. Journal of urban health, 2007, 84(1): 16-26. https://doi.org/10.1007/s11524-007-9169-3

[3] Wilson K, Dennison C, Struminger B, et al. Building a Virtual Global Knowledge Network during COVID-19: The Infection Prevention and Control Global Webinar Series. Clinical Infectious Diseases, 2021, 73(S1): 98-105. https://doi.org/10.1093/cid/ciab320

[4] Pandi-Perumal SR, Vaccarino SR, Chattu VK, et al. 'Distant socializing,' not 'social distancing' as a public health strategy for COVID-19. Pathogens and Global Health, 2021, 1-8. https://doi.org/10.1080/20477724.2021.1930713

[5] Chen X and Fan A. Pandemic Economics and the Transformation of Health Policy, 2021, 14061. https://ssrn.com/abstract=3775966

[6] Kontogiannis T. A qualitative model of patterns of resilience and vulnerability in responding to a pandemic outbreak with system dynamics. Safety Science, 2021, 134: 105077. https://doi.org/10.1016/j.ssci.2020.105077

[7] Yip W, Ge L, Ho AHY, et al. Building community resilience beyond COVID-19: The Singapore way. The Lancet Regional HealthWestern Pacific, 2021, 7: 100091. https://doi.org/10.1016/j.lanwpc.2020.100091

[8] Zhang J, Hayashi Y and Frank LD. COVID-19 and transport: findings from a world-wide expert survey. Transport policy, 2021, 103(C): 68-85. https://doi.org/10.1016/j.tranpol.2021.01.011

[9] World Health Organization. Strengthening preparedness for COVID-19 in cities and urban settings: interim guidance for local authorities (No. WHO/2019-nCoV/Urban preparedness/2020.1). World Health Organization, 2020. https://creativecommons.org/licenses/by-nc-sa/3.0/igo

[10] Han MJN and Kim MJ. A critical review of the smart city in relation to citizen adoption towards sustainable smart living. Habitat International, 2021, 108: 102312. https://doi.org/10.1016/j.habitatint.2021.102312

[11] Tanzini M, Romano E, Bonaventura A, et al. Coping with the COVID-19 Pandemic: Roles and Responsibilities for Preparedness. Textbook of Patient Safety and Clinical Risk Management, 2021, 485 .

https://doi.org/10.1007/978-3-030-59403-9

[12] Stylianou V. A policy response to COVID-19: An Australian perspective. Journal of the International Council for Small Business, 2021, 2(3): 1-8. https://doi.org/10.1080/26437015.2020.1852060

[13] Amoo EO, Adekeye O, Olawole-Isaac A, et al. Nigeria and Italy divergences in coronavirus experience: impact of population density. The Scientific World Journal, 2020, 8923036. https://doi.org/10.1155/2020/8923036

[14] Carozzi F. Urban density and COVID-19, 2020. https://ssrn.com/abstract=3643204

[15] Bereitschaft B and Scheller D. How Might the COVID-19 Pandemic Affect 21st Century Urban Design, Planning, and Development?. Urban Science, 2020, 4(4): 56. https://doi.org/10.3390/urbansci4040056

[16] Bouffanais R and Lim SS. Citiestry to predict superspreading hotspots for COVID-19, 2020.

[17] Shahraki AA. Supplying water in hydro-drought regions with case studies in Zahedan. Sustainable Water Resources Management, 2019, 5(2): 655-665. https://doi.org/10.1007/s40899-018-0229-5

[18] Shahraki AA. Water planning and management in sustainable new town building, the case of Ramshar. International Journal of Water Resources and Environmental Engineering, 2015, 7(9): 115-122. https://doi.org/10.5897/IJWREE2014.0558

[19] Weidhaas J, Aanderud ZT, Roper DK, et al. Correlation of SARS-CoV-2 RNA in wastewater with COVID-19 disease burden in sewer sheds. Science of The Total Environment, 2021, 145790. https://doi.org/10.1016/j.scitotenv.2021.145790 
[20] Shahraki AA. Collect and treat urban wastewater to fight the pandemic disease of COVID-19 effectively, 2021

https://doi.org/10.20944/preprints202010.0441.v2

[21] Espejo W, Celis JE, Chiang G, et al. Environment and COVID-19: Pollutants, impacts, dissemination, management and recommendations for facing future epidemic threats. Science of The Total Environment, 2020, 747: 141314

https://doi.org/10.1016/j.scitotenv.2020.141314

[22] Dube K, Nhamo G and Chikodzi D. COVID-19 pandemic and prospects for recovery of the global aviation industry. Journal of Air Transport Management, 2021, 102022. https://doi.org/10.1016/j.jairtraman.2021.102022

[23] Rassanjani S, Risky N, Maz D, et al. Impact of COVID-19 on Economic Activities and Poverty Threats in the Asia-Pacific Region. Policy \& Governance Review, 2021, 5(1): 82-96. https://doi.org/10.30589/pgr.v5i1.353

[24] OECD. Cities Policy Responses, 2020. https://www.oecd.org/coronavirus

[25] McCartney G, Pinto J and Liu M. City resilience and recovery from COVID-19: The case of Macao. Cities, 2021, 112: 103130.

https://doi.org/10.1016/j.cities.2021.103130 